\title{
From Seaweeds to Cosmeceutics: A Multidisciplinar Approach
}

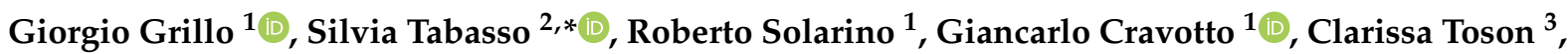 \\ Elena Ghedini $^{3}$, Federica Menegazzo ${ }^{3}(\mathrm{D})$ and Michela Signoretto ${ }^{3}$ (D) \\ 1 Department of Drug Science and Technology, University of Turin, 10125 Turin, Italy; \\ giorgio.grillo@unito.it (G.G.); roberto.solarino@unito.it (R.S.); giancarlo.cravotto@unito.it (G.C.) \\ 2 Department of Chemistry, University of Turin, Via Pietro Giuria 7, 10125 Turin, Italy \\ 3 CATMAT Lab, Department of Molecular Sciences and Nanosystems, Ca' Foscari University Venice and \\ INSTM Consortium RU Ve, 30170 Venice, Italy; cla.tsn994@gmail.com (C.T.); gelena@unive.it (E.G.); \\ fmenegaz@unive.it (F.M.); miky@unive.it (M.S.) \\ * Correspondence: silvia.tabasso@unito.it
}

Citation: Grillo, G.; Tabasso, S.; Solarino, R.; Cravotto, G.; Toson, C.; Ghedini, E.; Menegazzo, F.; Signoretto, M. From Seaweeds to Cosmeceutics: A Multidisciplinar Approach. Sustainability 2021, 13, 13443. https://doi.org/10.3390/ su132313443

Academic Editor: Paris Fokaides

Received: 25 October 2021

Accepted: 2 December 2021

Published: 4 December 2021

Publisher's Note: MDPI stays neutral with regard to jurisdictional claims in published maps and institutional affiliations.

Copyright: (c) 2021 by the authors. Licensee MDPI, Basel, Switzerland. This article is an open access article distributed under the terms and conditions of the Creative Commons Attribution (CC BY) license (https:/ / creativecommons.org/licenses/by/ $4.0 /)$.

\begin{abstract}
Macroalgae are widespread on the coasts of all the globe and lead to a negative ecological impact, requiring expensive remediations. Therefore, the valorization of invasive seaweed as a renewable source of bioactive products could represent a valid solution. In this context, three algal biomasses, belonging to brown, green, and red families (Sargassum muticum, Ulva lactuca, Solieria filiformis), collected in the venetian Laguna, were investigated as a source of active compounds for the formulation of cosmeceutics. Microwave (MW) and ultrasound (US) were applied to enhance the algae extraction by means of a hydroalcoholic solution. According to total phenolic content (TPC) evaluation, MW demonstrated the best performing outcomes, resulting in 19.77, 22.02, and $16.94 \mathrm{mg}_{\mathrm{GAE}} / \mathrm{g}_{\mathrm{Extr}}\left(30 \mathrm{~min}\right.$ at $\left.90^{\circ} \mathrm{C}\right)$ for brown, green, and red algae, respectively. Antioxidant activity was tested as well, showing comparable trends $\left(49.19,26.24\right.$, and $3.02 \mathrm{mmol}_{\text {Trolox }}$ eq. $/ \mathrm{g}_{\text {Extr }}$ for brown, green, and red algae, respectively). Due to natural algae predisposition to absorb contaminants, the metal content analysis helped to screen the applicability of these extracts, identifying Ulva lactuca as the most suitable source of antioxidants for cosmetic formulations. This MW extract was then adopted to formulate two different preparations, namely a gel and an emulsion. Thermal and mechanical tests confirmed the stability of each formulation, together with neutral organoleptic characteristics. Finally, the actives release was investigated by means of a tape stripping essay, showing an efficient controlled release for gel formulation, even after $7 \mathrm{~h}$ of test. The produced cosmeceutics merged non-conventional extraction technologies with formulation expertise, offering a valuable alternative to solve the macroalgae disposal issue.
\end{abstract}

Keywords: macroalgae; microwaves; dermo-cosmetic formulation; polyphenols; antioxidant activity; controlled release

\section{Introduction}

Macroalgae are widely distributed on the coasts of all the continents and have negative ecological and economic impacts in the aquaculture and tourism industries, requiring their removal by governmental agencies. However, the increasing demand of low-cost renewable feedstock combined with the need for environmental remediation has prompted the search for valorization processes of invasive seaweed in the context of a circular economy. This strategy could therefore represent the key to reduce its environmental issues by overcoming the limits related to its scarce commercial use [1]. Seaweed is indeed considered to be one of the richest marine sources of biologically active ingredients, suitable for several industrial applications in the pharmaceutical, cosmeceutical, and nutraceutical fields [2]. Indeed, macroalgae are rich in secondary metabolites such as vitamins, sterols, pigments, and phenolic compounds, such as catechins, flavonols, flavonolglycosides, phloroglucinol, gallic acid, epicatechin, pyrocatechol, gallate, flavonoids, anthocyanins, stilbenes, lignans, and phenolic polymers [3]. In the brown seaweeds, the phlorotannins are the 
major polyphenolic class found only in the marine brown seaweeds [4]. On the other hand, bromophenols, flavonoids, phenolics acids, phenolic terpenoids, and mycosporine-like amino acids represent the largest proportion of phenolic compounds present in green and red seaweeds [5]. These compounds could be an effective natural alternative to synthetic chemicals for cosmeceutical formulations. Indeed, this sector, referring to products endowed with both cosmetic and pharmaceutical effects [6], aims to improve skin appearance, structure, and functions, and is always looking for principally active molecules to replace harmful synthetic chemicals.

In this context, seaweeds show many skin benefits, such as moisture retention, cell renewal activation, cell metabolism, the regulation of sebaceous secretion and tissue drainage, promoting blood circulation, and increasing skin resistance [7]. Furthermore, the antioxidant properties of phenolic compounds and pigments present in seaweed (such as carotenoids and fucoxanthin) can prompt their application in anti-age formulations [8]. Therefore, natural compounds from seaweeds may represent a valid alternative in cosmeceutical formulations, being less toxic, non-carcinogenic, easily accessible, and economically beneficial [9]. The extraction of bioactives from macroalgae is currently performed with conventional methods, such as solid-liquid extraction [10], hydrodistillation, Soxhlet extraction [11-13]. However, long extraction times are required to achieve good yields, with the consequent possible degradation and the loss of bioactive compounds. Furthermore, these processes are usually high-energy demanding and costly for industrial applications, and involve the use of large volumes of toxic organic solvents. Owing to these limitations, more efficient and environmentally friendly techniques have been pursued in recent years, such as, for example, Microwave-Assisted Extraction (MAE) and Ultrasound-Assisted Extraction (UAE) [14,15]. Microwave heating, owing to the dipole rotation, causes the disruption of weak hydrogen bonds and the migration of dissolved ions, enhancing the penetration of the solvent into the matrix [16]. In addition, since it is often carried out in closed vessels, MAE allows working at higher temperatures than those achievable at atmospheric pressure in solid-liquid extractions. Therefore, high yields can be achieved in short reaction times, thus resulting in lower energy consumption and less products degradation. In addition, lower solid/liquid (S/L) ratios are required, and, consequently, lower solvent volume consumption. The most used solvent mixtures for MAE involved the use of ethanol and water $[17,18]$, although few authors have applied acetone: water mixtures [19]; methanol: water [20], or just water [21]. Pérez et al. optimized the MAE of phenolic compounds from wet Sargassum muticum in two stages, with a solvent-free extraction followed by a water extraction [22]. On the other hand, UAE is a non-thermal extraction method based on cavitation, which enhances solvent penetration into cellular materials, thus improving the mass transfer [23]. The sonomechanical effects result in the disruption of the biological membranes, resulting in the disruption of the biological membranes, and enhancing the release of the target compounds [24]. Several phenolic compounds have been extracted under UAE using methanol: water mixtures $[25,26]$.

The growing eco-consumerism requires sustainable processes for the development of new cosmetic ingredients and formulations, from biomass sourcing to the non-conventional extraction of natural active ingredients to be included in the new green formulation. Although the use of non-conventional extraction methods is not unknown in the context of algae valorization, the further direct application of the extracts thus obtained in a skin anti-age stable formulation is still underexplored.

In this context, the shortening of the supply chain by using local raw materials is a key factor. The consequent reduction of the supply and transportation costs, coupled with the reduced energy consumption by using non-conventional technologies improve the sustainability of the process and of the final products. This work described the valorization of different algal species widespread in the Venetian Lagoon, where they cause significant damage to the environment and tourism industries. Sustainable ultrasound- and microwave-assisted processes were designed in order to maximize the yields in polyphe- 
nols, which were then used as antioxidant natural ingredients in dermo-cosmetic, anti-age formulations.

\section{Materials and Methods}

\subsection{Chemicals \& Algal Biomass}

$\mathrm{EtOH}$ (ACS grade, $\geq 99 \%$ ), gallic acid (analytical standard), ICP multi-element standard solution IV (1000 ppm), Trolox ${ }^{\circledR}$, the 2,2-diphenyl-1-picrylhydrazyl radical (DPPH•), the Folin-Ciocalteu reagent, sodium carbonate, tetrahydroxysilane (TEOS) reagent grade, (98\%) methyltriethoxysilane (MTES) technical grade (90\%), glycolic acid, and chitosan were purchased from Merck-Sigma-Aldrich (Milan, Italy). MilliQ $\mathrm{H}_{2} \mathrm{O}$ was obtained in the laboratory using a Milli-Q Reference A + System (Merck Millipore, Darmstadt, Germany). Sodium alginate was purchased from Farmalabor (Assago, Milan, Italy). Pectin (E 440) was obtained from A.C.E.F. S.p.A (Fuorenzuola D'Arda, PC, Italy). Guar gum (Jaguar (HP-105)) was purchased from Solvay (Ixelles, NL) and the Extravirgin Olive Oil Bio (EVOO) from Naissance (Milland Road Industrial Estate, Milland Rd, Neath SA11 1NJ).

Three different algal species were collected in the Venice Lagoon: Sargassum muticum, Ulva lactuca, and Solieria filiformis, belonging to the groups of Heterokontophyta (brown algae), Chlorophyceae (green algae), and Rhodophyceae (red algae), respectively. The classification of the algae was based on taxonomically relevant morphological characteristics. After the harvesting, each sample was thoroughly washed with tap water to remove debris and salts. Algal biomass was dried for one week in the open air and then cryo-milled. Thermogravimetric analyses were then performed on dry matter to determine residual water and organic and inorganic fractions. In particular, $500 \mathrm{mg}$ of each sample were kept at $100{ }^{\circ} \mathrm{C}$ for $15 \mathrm{~h}$ to evaluate humidity loss. The resulting matrix was then heated at $650{ }^{\circ} \mathrm{C}$ for $4 \mathrm{~h}$ to quantify the volatile organic fraction and evaluate the residual ashes content. The same analysis was conducted on the dried extract to determine the organic/inorganic content. Each analysis was performed in triplicate.

\subsection{Microwave-Assisted Extraction (MAE)}

The algal biomass $(2 \mathrm{~g})$ was mixed with $30 \mathrm{~mL}$ of a hydroalcoholic solution $\left(\mathrm{EtOH} / \mathrm{H}_{2} \mathrm{O}\right.$ $70 / 30$ ), according to the S/L ratio of 1:15. The solvent composition was corrected for the biomass water content. The mixture was left to hydrate for $5 \mathrm{~min}$ in a $50 \mathrm{~mL}$ borosilicate vial, which was then introduced in a MW multimodal reactor (SynthWAVE, Milestone, Bergamo, Italy) able to exploit an external inert gas feeding $\left(\mathrm{N}_{2}\right)$. For each test, an appropriate purging with nitrogen was carried out three times to remove oxygen traces from the system, reducing oxidative degradation of the material. The reaction chamber was then pressurised with 2 bars of $\mathrm{N}_{2}$. The samples were heated to $90{ }^{\circ} \mathrm{C}$ (max. power $1500 \mathrm{~W}$ ) and the temperature maintained for $30 \mathrm{~min}$ under magnetic stirring $(650 \mathrm{rpm})$. The resulting solutions were then filtered under vacuum, washing the algal biomass three times with fresh hydroalcoholic solution ( $5 \mathrm{~mL}$ each). EtOH was evaporated under vacuum, whilst the remaining water was removed by freeze-drying (LyoQuest-85, Telstar, Spain). The dried material was weighed and stored at $4{ }^{\circ} \mathrm{C}$ for further analyses. Each extraction was performed in triplicate.

\subsection{Ultrasound-Assisted Extraction (UAE)}

UAE was performed using an immersion horn (HNG-20500-SP, Hainertec Suzhou, China), working at $500 \mathrm{~W}$ and $21 \mathrm{kHz}$.

The algal biomass ( $2 \mathrm{~g}$ ) was mixed with the proper amount of $60 \mathrm{~mL}$ of a hydroalcoholic solution $\left(\mathrm{EtOH} / \mathrm{H}_{2} \mathrm{O} 70 / 30\right)$, according to a S/L ratio of 1:30. The solution was placed in a Pyrex ${ }^{\circledR}$ thimble (r: $4 \mathrm{~cm}$ and h: $\left.19 \mathrm{~cm}\right)$. The temperature was monitored throughout the UAE, and heat exchange was provided by an ice bath. The solution was kept approx. at $40{ }^{\circ} \mathrm{C}$ to avoid losses in cavitation efficiency [27].

After the extraction, the resulting solutions were then filtered under vacuum, washing the algal biomass for three times with fresh hydroalcoholic solution ( $5 \mathrm{~mL}$ each). EtOH 
was evaporated under vacuum, whilst the remaining water was removed by freeze-drying (LyoQuest-85, Telstar, Spain). The dried material was weighed and stored at $4{ }^{\circ} \mathrm{C}$ for further analyses. Each extraction was performed in triplicate.

\subsection{Total Poliphenolic Content (TPC)—Folin-Ciocalteau}

TPC was determined according to the Folin-Ciocalteu method, as previously described [28]. Briefly, polyphenols quantification was performed by applying a calibration curve of gallic acid as reference compound (dilutions between 5 and $250 \mu \mathrm{g} / \mathrm{mL}$ ) in aqueous solutions. Dried extracts were dissolved in deionized water at a concentration of 4-6 mg/mL. The gallic acid and sample solutions $(250 \mu \mathrm{L})$ were placed into borosilicate test tubes. The following solutions were added sequentially for each test: $500 \mu \mathrm{L}$ of $\mathrm{Na}_{2} \mathrm{CO}_{3}$ solution $(10 \% \mathrm{~W} / \mathrm{V}), 4 \mathrm{~mL}$ of distilled water, and $250 \mu \mathrm{L}$ of Folin-Ciocalteu reagent (diluted 1:1 with distilled $\mathrm{H}_{2} \mathrm{O}$ ). The resulting mixtures were vigorously shaken and kept at room temperature for 25 min before the analysis. A Cary 60 UV-VIS spectrophotometer (Agilent Technologies, Santa Clara, CA, USA) was used to read the absorption at $740 \mathrm{~nm}$ in a quartz cuvette $(1 \mathrm{~cm})$. The TPC was expressed as $\mathrm{mg} / \mathrm{g}$ of gallic acid equivalents (GAE) over extract and over dried matrix. The measurements were performed in triplicate.

\subsection{Antioxidant Activity—DPPH}

The radical scavenging activity of the extracts was evaluated using the stable free radical DPPH•, according to the method described by Brand-Williams et al. [29]. Details of the procedure and calculations have already been reported in a previous work [30]. The bleaching rate of the DPPH• radical was monitored in the presence of macroalgae extracts and in a Trolox ${ }^{\circledR}$ (antioxidant standard for TEAC determination) solution, for sake of comparison, to evaluate the EC50 (half maximal concentration of extract necessary to halve the initial concentration of DPPH• at equilibrium). The radical scavenging activity of the Trolox ${ }^{\circledR}$ solutions was measured in concentrations from 1 to $18 \mu \mathrm{g} / \mathrm{mL}$, corresponding to $0.004,0.008,0.016,0.020,0.028,0.040,0.048$, and $0.072 \mu \mathrm{mol} / \mathrm{mL}$.

Various concentrations of extracts were analysed at $515 \mathrm{~nm}$ (Cary 60 UV-VIS spectrophotometer, Agilent Technologies, Santa Clara, CA, USA). Collected data were processed by Bobo Least Squares software (ver. 0.9.1.) [31] to establish an accurate probit regression $(\mathrm{R} \geq 0.96)$. Blank samples containing the extracts without the DPPH reactive were adopted to evaluate and subtract the matrix effect and avoid interferences at the analytical wavelength. The radical scavenging activity was expressed as mg compound/dried extract per $\mathrm{mL}$ solution. The Trolox ${ }^{\circledR}$ equivalents $\mathrm{mmol} / \mathrm{g}$ of the extract were calculated according to the EC50 values $\left(3.94 \mu \mathrm{g}\right.$ of Trolox ${ }^{\circledR} / \mathrm{mL}$, corresponding to $\left.0.0157 \mu \mathrm{mol}\right)$.

\subsection{Metal Content Evaluation}

Biomass metal content was determined by ICP analysis. In detail, $100 \mathrm{mg}$ of extract was dissolved in $5 \mathrm{~mL}$ of aqua regia. MilliQ water was used to reach an appropriate dilution for measurements. After $24 \mathrm{~h}$, the mixture was filtered and analysed with an Agilent MP-AES 4210 (Microwave Plasma-Atomic Emission Spectrometer). Results were expressed depending on calibration curves obtained by $0.5,2,5,10 \mathrm{ppm}$ milliQ solution of a proper stock standard solution. The analyses were performed in triplicate.

\subsection{Formulation}

The base applied to formulate the cosmetic products with the algal extract and the resulting cosmeceutics were prepared with materials listed in supplementary materials Table S1 (INCI included).

For the cosmetic formulation, an inorganic and an organic suspension were prepared. The latter was subjected to formulation optimization as well as for polysaccharides additions (type and ratios), depending on the type of desired product (gel or emulsion).

Sodium alginate $(\mathrm{A})$, pectin (Pe), and chitosan $(\mathrm{Ch})$ were exploited as complementary natural biopolymers, investigating the most suitable ratio for a cosmetic formulation. The 
optimised composition in terms of texture and spreadability was reported in Table 1 and Figure 1.

Table 1. Cosmetic base optimized percentage composition.

\begin{tabular}{ccccccccc}
\hline Cosmetic Base $^{\text {a }}$ & A & Ch & Pe & Gly & G & O & W & Si \\
\hline & 0.2 & 1.5 & 0.3 & 2 & 0.5 & 7 & 85 & 4
\end{tabular}

a (A) Sodium alginate; (Ch) Chitosan; (Pe) Pectin; (Gly) Glycolic acid; (G) Guar gum; (O) Extra virgin olive oil. W: water; Si: silica.

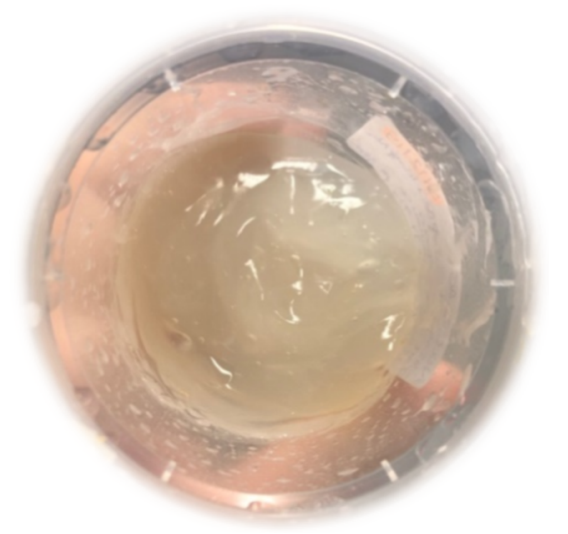

Figure 1. Final texture of the cosmetic base.

TEOS and MTES were combined with MilliQ water and an acid catalyst was added, obtaining a sol-gel mixture. In parallel, glycolic acid, polysaccharides (chitosan, alginate, and pectin), guar gum, and algal extract were dissolved in MilliQ water. The two mixtures were combined under vigorous agitation, generating a suspension that was added with EVOO as moisturizing. Gel reticulation was concluded, aging the product for $15 / 20$ days. Finally, $\mathrm{pH}$ was adjusted to 4.5 and 5.5 by means of an alkaline solution.

Stability tests were performed, accelerating the natural aging of the cosmetic during storage and use. Samples were subjected to thermal and mechanical stress. Mechanical stress was provided by centrifugation at $4800 \mathrm{rpm}$ for $30 \mathrm{~min}$. Thermal stress, instead, was provided by warm/cold cycles. In detail, formulates were maintained at $40{ }^{\circ} \mathrm{C}$ for $30 \mathrm{~min}$ and then at $4{ }^{\circ} \mathrm{C}$ for another $30 \mathrm{~min}$. This cycle was repeated three times. These temperatures were adopted for simulating usual storage and use conditions. After the three cycles, one fraction of the tested samples was placed at $4{ }^{\circ} \mathrm{C}$ for two weeks and one fraction was placed at $40{ }^{\circ} \mathrm{C}$ for the same period. At the end of the stability tests, organoleptic properties were evaluated, namely colour, odour, $\mathrm{pH}$, and viscosity. In particular, the $\mathrm{pH}$ was evaluated with a Metrohon $\mathrm{pH}$ meter at $25^{\circ} \mathrm{C}$. As acceptance criteria, formulations with $\mathrm{pH}$ value variations higher than $15 \%$, after comparing with the initial value, were reproved [32,33]. Rheology analyses were run to measure the viscosity of the different coatings. For each sample, around $5 \mathrm{~mL}$ had to be poured inside the rheometer set at $25^{\circ} \mathrm{C}$ plate by using a conic geometry. The instrument used for these analyses was a Modular Compact Rheometer (MCR 102) from the Anton Paar GmbH.

\subsection{Formulation Efficacy-Tape Stripping}

The evaluation of formulates efficacy was performed by means of a tape stripping test, applying a Franz-type diffusion cell. This system is used to investigate actives skin permeation and cutaneous retention of transdermal and topic applications. Pig ears are adopted as ex vivo membranes, prepared as previously reported [34].

A known amount of formulate $(0.215 \mathrm{~g})$ was spread on the membrane, held in the donor section of the cell by a metallic net. The acceptor section was loaded in a physiologic solution at pH 7.4 (PBS, Tris Buffered Saline), kept at $37^{\circ} \mathrm{C}$ under stirring. Contact between physiologic solution and the membrane was carefully ensured, sealing the system to 
avoid evaporation. Every sample was tested for 1, 3, 5, and $7 \mathrm{~h}$ of release. The tape stripping assay was then performed as previously reported [35]. In brief, after the desired amount of time, the membrane was removed from the cell and cleaned from the exceeding depositions with a spatula. A $2 \mathrm{~cm} \times 1.5 \mathrm{~cm}$ tape was then applied and wiped on the surface 10 times to remove the stratum corneum. The pig heart and the tape were transferred into vials filled with $10 \mathrm{~mL}$ of $\mathrm{EtOH}$ to recover the adsorbed actives. These vials were left at $40{ }^{\circ} \mathrm{C}$ in a US bath for $2 \mathrm{~h}$. Solutions were filtered and stored at $4{ }^{\circ} \mathrm{C}$ before the analysis. Ethanolic solutions were tested with a Cary 60 UV-VIS spectrophotometer (Agilent Technologies, Santa Clara, CA, USA), reading absorption at $203 \mathrm{~nm}$ for the green algae extract. Quantifications were derived from a calibration curve obtained from Ulva lactuca extract standard concentration (range 0-1500 ppm).

\section{Results and Discussion}

\subsection{Non-Conventional Macroalgae Extraction}

Before the non-conventional extractions, the three algal species were characterised by thermogravimetric analyses to determine the water and the organic and inorganic content (Table 2), as described in Section 2.1.

Table 2. Algal biomass thermogravimetric analyses.

\begin{tabular}{ccccccccc}
\hline Sample & Water (\%) & $\begin{array}{c}\text { SD } \\
\mathbf{( \% )}\end{array}$ & $\begin{array}{c}\text { Organic } \\
\text { Content (\%) }\end{array}$ & $\begin{array}{c}\text { SD } \\
\mathbf{( \% )}\end{array}$ & Ashes (\%) & $\begin{array}{c}\text { SD } \\
\mathbf{( \% )}\end{array}$ & $\begin{array}{c}\text { Organic }^{\mathbf{\%}} \\
\text { Content }^{\mathbf{a}} \mathbf{( \% )}\end{array}$ & $\begin{array}{c}\text { Ashes } \\
\mathbf{( \% )}\end{array}$ \\
\hline Sargassum muticum & 23.93 & \pm 0.43 & 63.94 & \pm 0.98 & 12.14 & \pm 0.44 & 84.05 & 15.95 \\
Ulva lactuca & 20.41 & \pm 0.51 & 65.40 & \pm 1.02 & 14.19 & \pm 0.69 & 82.17 & 17.83 \\
Solieria filiformis & 24.67 & \pm 0.39 & 57.53 & \pm 1.03 & 17.80 & \pm 0.97 & 76.37 & 23.63 \\
\hline
\end{tabular}

${ }^{a}$ Organic and inorganic fractions percentages on dry biomass. All analyses were performed in triplicate and results expressed as the average \pm SD.

MAE and UAE were then tested according to previously optimized extraction parameters $[36,37]$ to determine the most efficient approach to recover metabolites from algal biomasses. The extraction times applied in this work were lower compared to the examples reported in literature for both MAE and UAE of macroalgae [18,25]. Therefore, although the temperature of the microwave-assisted treatment was higher, the risk of thermal and oxidative degradation of bioactive compounds was averted by the lower residence time and the presence of an inert atmosphere. In literature, it is common to find numerous studies where the extraction procedures used for phlorotannin recovery and analysis from brown algae take about $24 \mathrm{~h}$, which is very time consuming [38].

Firstly, process outcomes were investigated by means of extraction yields expressed on dry matrix (DM, see Table 3). In general, the highest amount of extract was recovered from the treatment of brown algae, according to the sequence Brown $>$ Green $>$ Red. This result is in accordance with the previous literature describing the brown seaweed as the major source of bioactive phenolic compounds (namely, fucoxanthin and various pheophycean tannins) [39].

Table 3. Extraction yield of algae, calculated on dry matrix.

\begin{tabular}{|c|c|c|c|c|c|c|}
\hline \multirow{2}{*}{ Extraction Technology } & \multicolumn{2}{|c|}{ Algae } & \multicolumn{4}{|c|}{ Extraction Yield $^{\text {a }}$} \\
\hline & Name & Type & $\mathrm{mg} / \mathrm{g}$ & SD & $\%$ & SD \\
\hline \multirow{3}{*}{$\mathrm{MAE}^{\mathrm{b}}$} & Sargassum muticum & Brown & 334.21 & \pm 12.10 & 33.42 & \pm 1.21 \\
\hline & Ulva lactuca & Green & 221.38 & \pm 8.43 & 22.14 & \pm 0.84 \\
\hline & Solieria filiformis & Red & 92.053 & \pm 5.99 & 9.21 & \pm 0.60 \\
\hline \multirow{3}{*}{$\mathrm{UAE}^{\mathrm{c}}$} & Sargassum muticum & Brown & 260.13 & \pm 8.02 & 26.01 & \pm 0.80 \\
\hline & Ulva lactuca & Green & 228.75 & \pm 10.19 & 22.88 & \pm 1.02 \\
\hline & Solieria filiformis & Red & 78.15 & \pm 4.20 & 7.81 & \pm 0.42 \\
\hline
\end{tabular}

${ }^{a}$ Dry matrix; ${ }^{\mathrm{b}} 90^{\circ} \mathrm{C}, 30 \mathrm{~min}, \mathrm{EtOH} / \mathrm{H}_{2} \mathrm{O} 70: 30, \mathrm{~S} / \mathrm{L}$ ratio $1: 15 ;{ }^{\mathrm{c}} 40^{\circ} \mathrm{C}, 30 \mathrm{~min}, \mathrm{EtOH} / \mathrm{H}_{2} \mathrm{O}$ 70:30, S/L ratio 1:30. All analyses were performed in triplicate and results expressed as the average $\pm \mathrm{SD}$. 
Furthermore, it is possible to notice that MAE allows slightly better outcomes, compared to UAE ( $33.42 \%$ vs. $26.01 \%, 22.14 \%$ vs. $22.88 \%$, and $9.21 \%$ vs. $7.81 \%$, respectively, for MAE and UAE, for the algal biomass listed according to Table 3 ). Nonetheless, to better understand the nature of the obtained extract, the polyphenolic content and the antioxidant activity were determined.

\subsection{Total Poliphenolic Content (TPC)—Folin-Ciocalteau Essay}

The analysis performed with the Folin-Ciocalteau essay allowed the determination of the average content of polyphenolic compounds of the algae extracts. Unfortunately, the content of phenolics in UAE extracts was undetectable due to an overwhelming matrix effect.

Indeed, the performance of UAE as the most efficient technology for the extraction of phenolic compounds is not clearly defined [40]. Some authors evidenced that the response to UAE was species-dependent, and that a matrix pretreatment was sometimes needed [41]. Despite these results, the extraction yields were not negligible, (See Section 3.3), suggesting that acoustic cavitation could probably prompt the extraction on polysaccharides and salts. For this reason, the investigation was focused on MAE, which showed interesting TPC results (See Table 4).

Table 4. TPC Yields and ashes content of samples after MAE.

\begin{tabular}{|c|c|c|c|c|c|c|c|c|}
\hline \multicolumn{2}{|c|}{ Algal Sample } & \multicolumn{4}{|c|}{ TPC Yield on DM * } & \multicolumn{2}{|c|}{ TPC Yield on Organic Fraction } & \multirow{2}{*}{$\begin{array}{c}\text { Ashes } \\
(\%)\end{array}$} \\
\hline Name & Type & $\mathrm{mg}_{\mathrm{GAE}} / \mathrm{g}_{\mathrm{Extr}}$ & SD & $\mathrm{mg}_{\mathrm{GAE}} / \mathrm{g}_{\text {Matrix }}$ & SD & $\mathrm{mg}_{\mathrm{GAE}} / \mathrm{g}_{\mathrm{Extr}}$ & $\mathrm{mg}_{\mathrm{GAE}} / \mathrm{g}_{\text {Matrix }}$ & \\
\hline Sargassum muticum & Brown & 19.77 & \pm 0.52 & 6.61 & \pm 0.17 & 25.88 & 7.86 & 23.60 \\
\hline Ulva lactuca & Green & 22.02 & \pm 0.84 & 4.87 & \pm 0.19 & 41.14 & 5.93 & 46.48 \\
\hline Solieria filiformis & Red & 16.94 & \pm 0.90 & 1.56 & \pm 0.08 & 17.97 & 2.04 & 5.71 \\
\hline
\end{tabular}

* Dry matrix. All analyses were performed in triplicate and results expressed as the average \pm SD.

To better describe the process outcomes, TPC were expressed both on extracts and on matrix weight. The first value is useful to define the extraction selectivity: higher results define extracts rich in polyphenols and with low amounts of other by products. The TPC yield expressed on dry matrix, on the other hand, can clearly depict how efficient the extraction protocol is, reporting how many polyphenols can be recovered from the starting material.

Generally, the extraction yield trend Brown $>$ Green $>$ Red is maintained as concerns the matrix, while Ulva lactuca showed a slightly higher TPC selectivity on dry matter, related to the lower extraction yield (22.02 $\mathrm{mg}_{\mathrm{GAE}} / \mathrm{g}_{\mathrm{Extr}}$ vs. $19.77 \mathrm{mg} \mathrm{g}_{\mathrm{GAE}} / \mathrm{g}_{\mathrm{Extr}}$, and $16.94 \mathrm{mg}_{\mathrm{GAE}} / \mathrm{g}_{\mathrm{Extr}}$, respectively, for Sargassum muticum and Solieria filiformis). Most of the literature examples reported the phenolic content with respect to the dry biomass, but this information does not shed light on the extraction efficacy of bioactives present in the native biomass and does not consider the effect of ashes on extraction yields. Therefore, due to the non-negligible number of ashes contained in the starting material (15-25\% on $\mathrm{DM}$, see Section 2.1), results were recalculated, considering only the organic fraction (See Table 4), to better understand the process productivity in terms of secondary metabolites that could actually be extracted from the matrix. This evaluation is possible thanks to thermogravimetric analysis (see Section 2.1) performed directly on the extracted material (Supplementary materials Table S2). As expected, the overall yields underwent a dramatic increase, particularly for green algae, which are richer in ashes (See Table 4).

\subsection{Antioxidant Activity-DPPH.}

Further analyses were performed on samples from MAE to define the antioxidant activity of recovered metabolites. As is well known, EC50 values define the amount of extract necessary to reduce the $50 \%$ the radical concentration (DPPH.); hence, the lower is this value, in terms of $\mathrm{mg} / \mathrm{mL}$, the higher is the antioxidant activity. DPPH essay (Table 5, Supplementary materials Figures S1-S3) confirmed that the brown algae Sargassum muticum is the most promising algal biomass for further valorization, followed by the green algae 
Ulva lactuca, while Solieria filiformis (red algae) is endowed with lower antioxidant properties. Since the antioxidant activity is correlated with the different metabolic activity of microalgae species and the active oxygen in culture [42], blank experiments were performed to evaluate the matrix effect and remove the eventual interferences due to chromophores absorbing at a diagnostic wavelength.

Table 5. Antioxidant activity for samples from MAE.

\begin{tabular}{ccccc}
\hline \multicolumn{2}{c}{ Algal Sample } & & EC50 & Trolox $^{\circledR}$ Eq. \\
\hline Name & Type & $\mathbf{m g} / \mathbf{m L}$ & Confidence Limit & mmol $_{\text {Trolox eq }} / \mathbf{g}_{\text {Extr }}$ \\
\hline Sargassum muticum & Brown & 0.32 & $0.09-3.23$ & 49.19 \\
Ulva lactuca & Green & 0.60 & $0.51-0.72$ & 26.24 \\
Solieria filiformis & Red & 5.22 & $3.04-10.36$ & 3.02 \\
\hline
\end{tabular}

Trolox ${ }^{\circledR}$ was used as benchmark to evaluate the corresponding antioxidant activity, according to a dedicated calibration curve. Results, reported as mmol of Trolox ${ }^{\circledR}$ eq. on $g$ of extract, are useful to directly depict the activity trend (inversely related to EC50), and confirm the promising properties of Sargassum muticum.

\subsection{Metal Content Evaluation}

Besides the valuable content of bioactive compounds (polyphenols, pigments, and polysaccharides), algae possess the ability to accumulate toxic elements, such as metals [43]. For this reason, in this work, we also investigated the presence of toxic elements inside of the recovered extract, as the seaweed was collected in an area with a strong anthropogenic impact on the environment. Due to the low amount of polyphenols and the scarce antioxidant effect, red algae were not considered suitable for further exploitation in the context of their possible valorization. The main results are reported in Table 6.

Table 6. Metal contents in extracts from MAE expressed as ppm (mg metal/ kg extr.).

\begin{tabular}{cccccccc}
\hline & \multicolumn{7}{c}{ Metal (ppm) } \\
\hline Seaweed & Type & Ni & $\mathbf{P b}$ & $\mathbf{C r}$ & $\mathbf{C d}$ & $\mathbf{C o}$ & As \\
\hline $\begin{array}{c}\text { Sargassum muticum } \\
\text { Ulva lactuca }\end{array}$ & Brown & 4630 & - & 9590 & 2.5 & 74.2 & - \\
\hline
\end{tabular}

Arsenic was not detected in any sample, whilst $\mathrm{Pb}$ was below the detection limits in brown algae, as well as $\mathrm{Cd}$ and $\mathrm{Co}$ in Ulva lactuca. However, the higher total metal content was detected in Sargassum muticum. The morphological and metabolic features of this class of seaweed could be responsible for a major predisposition of brown algae to metal bio-absorption. Indeed, the high porosity and high surface/volume ratio of thalli, together with the large concentration in alginates, could partially explain the easy permeation and fixation of ionic species [44,45].

Aiming to exploit the algae extracts for cosmeceutics applications, the legal limit of metal tolerated in the final formulation has to be taken into consideration.

Commonly, the percentage amount of plant extracts in dermo-cosmetics accounts for $0.1 \%$ up to $1 \%$. For this reason, the metal content reported in Table 6 for the raw extracts should be normalized depending on the proper extract amount added to the formulation. For our purposes, the suitable amount of extract to be considered is $1 \%$, in order to take advantage of the metabolites' activity. With this premises, Table 7 describes the legal limits according to Article 17 of the European Regulation for Cosmetics [46], together with the metal normalization for the formulation ( $1 \%$ of extract added to $1 \mathrm{~kg}$ of cosmetic). 
Table 7. Algae extract metal content for $1 \%$ addition to a cosmetic formulation and accepted limits.

\begin{tabular}{|c|c|c|c|c|c|c|c|}
\hline \multirow[b]{2}{*}{ Name } & \multirow[b]{2}{*}{ Type } & \multicolumn{6}{|c|}{ mg Metal /kg Cosmetic (ppm) } \\
\hline & & $\mathbf{N i}$ & $\mathbf{P b}$ & $\mathrm{Cr}$ & $\mathrm{Cd}$ & Co & As \\
\hline Sargassum muticum & Brown & 46.3 & - & 95.9 & 0.025 & 0.74 & - \\
\hline Ulva lactuca & Green & 0.15 & 0.141 & 0.025 & - & - & - \\
\hline \multicolumn{2}{|c|}{ Accepted Limits } & 10 & 20 & 1 & 5 & 5 & 1 \\
\hline
\end{tabular}

According to the above-reported results, green algae do not show exceeding metal contents. On the other hand, for brown algae, $\mathrm{Ni}$ and $\mathrm{Cr}$ amounts are largely higher than the accepted limits (46.3 ppm over $10 \mathrm{ppm}$ and $95.9 \mathrm{ppm}$ over $1 \mathrm{ppm}$, for $\mathrm{Ni}$ and $\mathrm{Cr}$, respectively), making this extract unsuitable for cosmeceutical applications (with $1 \%$ of extract in the formulation). However, the high concentration of polyphenols and the promising antioxidant activity make Sargassum muticum an interesting algal biomass, hence it is possible to suggest a different harvesting location to reduce metals contamination. This solution could help to exploit a very promising matrix for dermo-cosmetic sustainable applications in the future. Considering all the gathered data, the MW extract of green algae was selected as a natural active component for the formulation of a cosmetic product.

\subsection{Formulation}

The development of a cosmetic product, designed with natural components suitably derived from biomass valorization, fits with sustainability and contemporary market requirements. However, the insertion of these types of materials could interfere with physico-chemical and sensorial features of the final product due to the complexity of natural extracts. Thus, during this work, the stability, the efficacy, and the organoleptic properties of formulations were monitored. The initial approach was based on a patented protocol, [47] modified accordingly to the Phyto metabolites of algal extracts. In particular, algae are rich in polysaccharides, such as alginates and pectins. For this reason, the original chitosan base was partially replaced with these two structural metabolites.

Alginates are biodegradable and biocompatible, and they can be exploited as stabilizers, thickening and jellying agents, in addition to their known properties of controlled release $[48,49]$.

Similarly, pectins are endowed with the same biological compatibility of alginates, together with stabilizing, jellying, and emulsifier and moisturizing features [50].

Briefly, we decided to exploit sodium alginate (A), pectin (Pe), and chitosan (Ch) as complementary natural biopolymers, investigating the most suitable ratio for a cosmetic formulation (Supplementary materials Table S1). Once a base with the desirable features was obtained, the next step was the addition of the Ulva lactuca (green algae) extract (Figure 2a). In particular, two different cosmetic formulations were prepared: a gel (Figure 2b, water dispersed in solid) and an emulsion Figure 2c (where the aqueous fraction is provided by the gel).

Firstly, it is worthy to note that, after the addition of the extract, the final product maintained a neutral odour and colour, together with a pleasant texture. Thus, the two preparations were characterized for their stability and the efficacy.

Formulate stability is a key feature, crucial for the evaluation of product shelf-life. In particular, the samples underwent an ageing process, followed by mechanical and thermal tests. Each sample proved stable after the centrifugation (30 min, $4800 \mathrm{rpm})$, and no separations were detectable either before or after the thermal cycles $\left(30 \mathrm{~min} @ 40^{\circ} \mathrm{C} / 30 \mathrm{~min}\right.$ @ $4{ }^{\circ} \mathrm{C}$ ). The $\mathrm{pH}$ was monitored after every step as well, confirming chemical stability. A longer thermal treatment was performed for 2 weeks, with no sensible differences. After the accelerated ageing, rheological properties of the samples were investigated, showing a pseudoplastic behavior. In addition, even after the hot/cold cycle, viscosity was not affected $\left(9.5 \cdot 10^{-6} \mathrm{~Pa} \cdot \mathrm{s}^{-1}\right)$. 


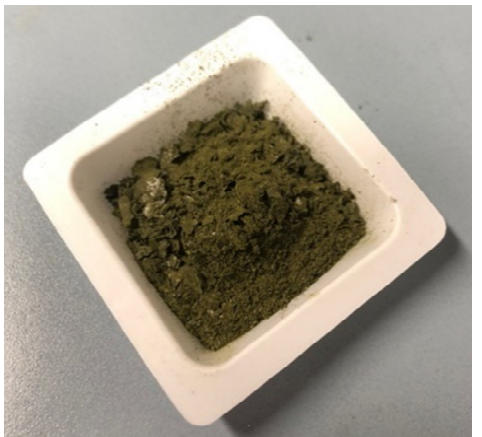

(a)

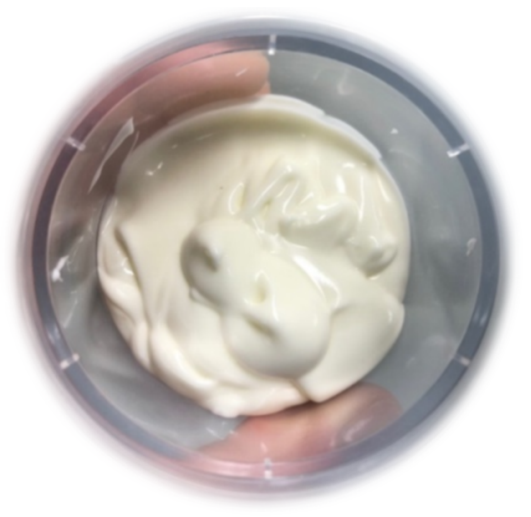

(b)

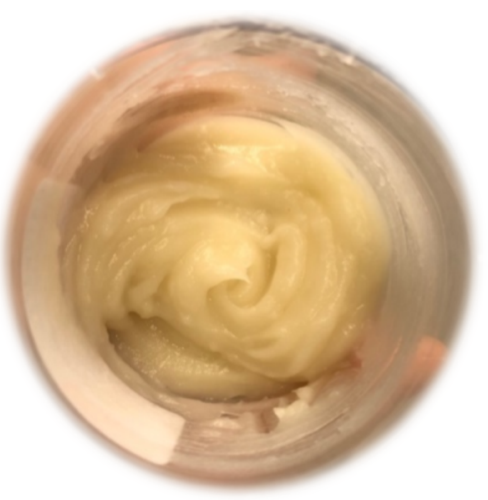

(c)

Figure 2. Active ingredients and formulates (a) Green algae (Ulva lactuca) extract, (b) Gel; (c) Emulsion.

\subsection{Formulate Efficacy-Tape Stripping}

The tape stripping test was selected to study the efficacy of the formulations. In detail, the penetration of the algal extract through the skin (epidermis and derma) was investigated using a Franz cell (See Section 2.8). The reported results describe the time evolution of the percentual concentration of extract permeate through the membrane ex vivo (Figure 3).

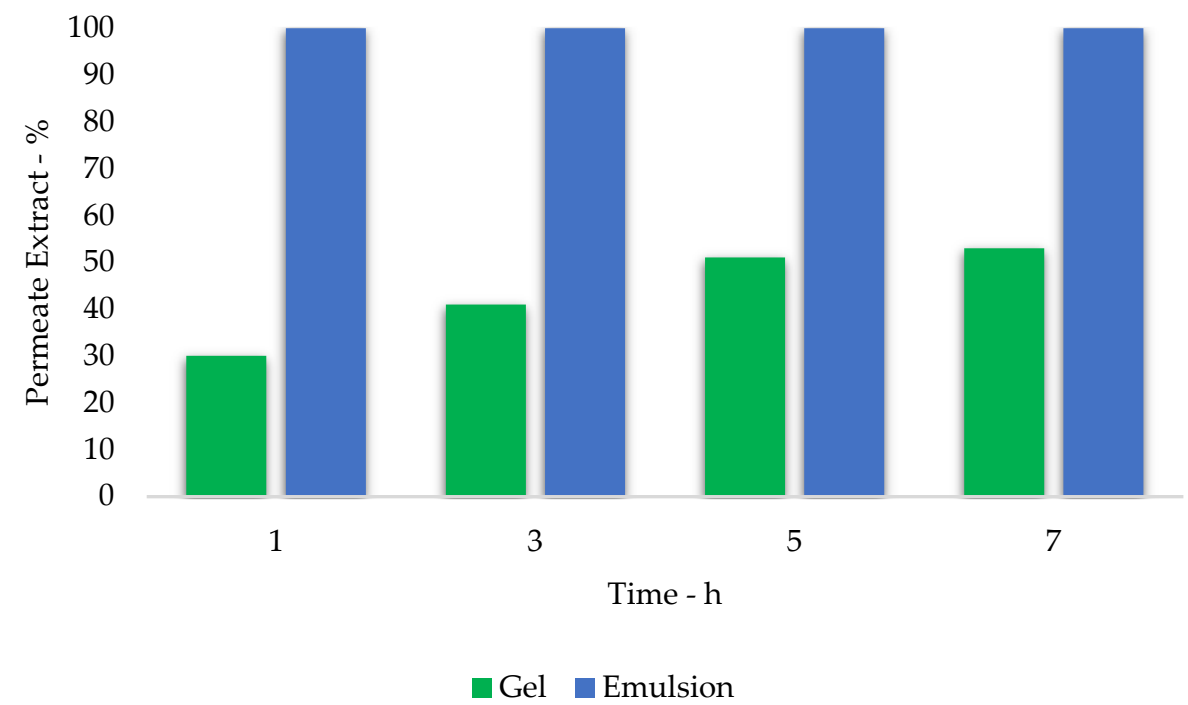

Figure 3. Formulate efficacy: tape stripping results obtained by Franz cell for gel and emulsion cosmetic formulations.

The observed trends are significantly different for gel and emulsion. Indeed, the first formulation allowed a controlled release of the actives, whilst the second led to an immediate permeation of all the extract after the first hour of testing. This phenomenon may be explained by a higher concentration of lipophilic compounds, more similar to the skin hydrolipidic film [35,51]. In addition, it can be assumed that, for the emulsion sample, the lipophilic fraction could lead to a partial collapse of the base polymeric network, which provides the controlled release.

\section{Conclusions}

Three different algal biomasses (Sargassum muticum, Ulva lactuca, and Solieria filiformis), collected in the Venice lagoon, were investigated as a source of antioxidant compounds. Non-conventional extraction methods were investigated to make the process more sus- 
tainable. Despite both UAE and MW allowing a noticeable time reduction and similar extraction yields, MW showed the best results in polyphenolic content. The extract from the green algae Ulva lactuca was selected for further cosmeceutic applications, as it showed good antioxidant properties and a low content of toxic metals. Two stable dermo-cosmetic preparations, a gel and an emulsion, were therefore prepared. In particular, the gel formulation showed the best results in terms of active controlled release. This work demonstrated an integrated sustainable valorization protocol for seaweed recovered from venetian Laguna areas, exploited as a source of active metabolites for stable anti-age skin cosmeceutics. These findings can therefore represent a proof-of-concept for a multidisciplinary and synergic approach, merging non-conventional extraction techniques with formulation expertise in the context of seaweed valorization.

Supplementary Materials: The following are available online at https:/ / www.mdpi.com/article/ 10.3390/su132313443/s1, Figure S1: DPPH essay for MAE extract of Sargassum muticum. Probit regression, relative equation and EC50 value. Measurements were performed according to Paragraph 2.5 in the Experimental Section. Figure S2: DPPH essay for MAE extract of Ulva lactuca. Probit regression, relative equation and EC50 value. Measurements were performed according to Paragraph 2.5 in the Experimental Section. Figure S3: DPPH essay for MAE extract of Solieria filiformis. Probit regression, relative equation and EC50 value. Measurements were performed according to Paragraph 2.5 in the Experimental Section. Table S1: Base and formulates materials. Table S1: Base and formulates materials. Table S2: Thermogravimetric analysis of MAE extract.

Author Contributions: Conceptualization, M.S. and S.T.; methodology, G.G. and E.G.; formal analysis, C.T. and R.S.; formulation F.M., E.G., M.S.; writing-original draft preparation, G.G. and S.T.; writing-review and editing, M.S.; F.M.; Supervision, G.C. All authors have read and agreed to the published version of the manuscript.

Funding: This work was supported by the University of Turin (Ricerca locale 2021).

Acknowledgments: This work was supported by the University of Turin (Ricerca locale 2021).

Conflicts of Interest: The authors declare no conflict of interest.

\section{References}

1. Milledge, J.J.; Maneein, S.; López, E.A.; Bartlett, D. Sargassum inundations in Turks and Caicos: Methane potential and proximate, ultimate, lipid, amino acid, metal and metalloid analyses. Energies 2020, 13, 1523. [CrossRef]

2. Kalasariya, H.S.; Yadav, V.K.; Yadav, K.K.; Tirth, V.; Algahtani, A.; Islam, S.; Gupta, N.; Jeon, B.-H. Seaweed-Based Molecules and Their Potential Biological Activities: An Eco-Sustainable Cosmetics. Molecules 2021, 26, 5313. [CrossRef] [PubMed]

3. Jormalainen, V.; Honkanen, T. Variation in natural selection for growth and phlorotannins in the brown alga Fucus vesiculosus. J. Evol. Biol. 2004, 17, 807-820. [CrossRef] [PubMed]

4. Heo, S.J.; Park, E.J.; Lee, K.W.; Jeon, Y.J. Antioxidant activities of enzymatic extracts from brown seaweeds. Bioresour. Technol. 2005, 96, 1613-1623. [CrossRef]

5. Cotas, J.; Leandro, A.; Monteiro, P.; Pacheco, D.; Figueirinha, A.; Gonçalves, A.M.M.; da Silva, G.J.; Pereira, L. Seaweed Phenolics: From Extraction to Applications. Mar. Drugs 2020, 18, 384. [CrossRef]

6. Jesumani, V.; Du, H.; Aslam, M.; Pei, P.; Huang, N. Potential Use of Seaweed Bioactive Compounds in Skincare-A Review. Mar. Drugs 2019, 17, 688. [CrossRef] [PubMed]

7. Gupta, S.; Abu-Ghannam, N. Bioactive potential and possible health effects of edible brown seaweeds. Trends Food Sci. Technol. 2011, 22, 315-326. [CrossRef]

8. Pereira, L. Seaweeds as Source of Bioactive Substances and Skin Care Therapy-Cosmeceuticals, Algotheraphy, and Thalassotherapy. Cosmetics 2018, 5, 68. [CrossRef]

9. Siahaan, E.A.; Pangestuti, R.; Munandar, H.; Kim, S.-K. Cosmeceuticals Properties of Sea Cucumbers: Prospects and Trends. Cosmetics 2017, 4, 26. [CrossRef]

10. Catarino, M.D.; Silva, A.M.S.; Mateus, N.; Cardoso, S.M. Optimization of phlorotannins extraction from Fucus vesiculosus and evaluation of their potential to prevent metabolic disorders. Mar. Drugs 2019, 17, 162. [CrossRef]

11. Santos, S.A.O.; Félix, R.; Pais, A.C.S.; Rocha, S.M.; Silvestre, A.J.D. The Quest for Phenolic Compounds from Macroalgae: A Review of Extraction and Identification Methodologies. Biomolecules 2019, 9, 847. [CrossRef] [PubMed]

12. Grosso, C.; Valentão, P.; Ferreres, F.; Andrade, P.B. Alternative and efficient extraction methods for marine-derived compounds. Mar. Drugs 2015, 13, 3182-3230. [CrossRef]

13. Vijayan, R.; Chitra, L.; Penislusshiyan, S.; Palvannan, T. Exploring bioactive fraction of Sargassum wightii: In vitro elucidation of angiotensin-I-converting enzyme inhibition and antioxidant potential. Int. J. Food Prop. 2018, 21, 674-684. [CrossRef] 
14. Zhao, G.; Chen, X.; Wang, L.; Zhou, S.; Feng, H.; Chen, W.N.; Lau, R. Ultrasound assisted extraction of carbohydrates from microalgae as feedstock for yeast fermentation. Bioresour. Technol. 2013, 128, 337-344. [CrossRef]

15. Wong, Y.C.; Shahirah, R. Effect of Different Solvent and Ratio Towards Microalgae Oil Production by Ul-trasonic Assisted Soxhlet Extraction Techniques. Orient. J. Chem. 2019, 35, 1377-1383. [CrossRef]

16. Routray, W.; Orsat, V. Microwave-Assisted Extraction of Flavonoids: A Review. Food Bioprocess Technol. 2012, 5, 409-424. [CrossRef]

17. He, Z.; Chen, Y.; Chen, Y.; Liu, H.; Yuan, G.; Fan, Y.; Chen, K. Optimization of the microwave-assisted extraction of phlorotannins from Saccharina japonica Aresch and evaluation of the inhibitory effects of phlorotannin-containing extracts on HepG2 cancer cells. Chin. J. Oceanol. Limnol. 2013, 31, 1045-1054. [CrossRef]

18. Li, Z.; Wang, B.; Zhang, Q.; Qu, Y.; Xu, H.; Li, G. Preparation and antioxidant property of extract and semipurified fractions of Caulerpa racemosa. J. Appl. Phycol. 2012, 24, 1527-1536. [CrossRef]

19. Safari, P.; Rezaei, M.; Shaviklo, A.T. The optimum conditions for the extraction of antioxidant compounds from the Persian Gulf green algae (Chaetomorpha sp.) using response surface methodology. J. Food Sci. Technol. 2015, 52, 2974-2981. [CrossRef] [PubMed]

20. Yuan, Y.; Zhang, J.; Fan, J.; Clark, J.; Shen, P.; Li, Y.; Zhang, C. Microwave assisted extraction of phenolic compounds from four economic brown macroalgae species and evaluation of their antioxidant activities and inhibitory effects on -amylase, -glucosidase, pancreatic lipase and tyrosinase. Food Res. Int. 2018, 113, 288-297. [CrossRef] [PubMed]

21. Michalak, I.; Tuhy, Ł.; Chojnacka, K. Seaweed extract by microwave assisted extraction as plant growth biostimulant. Open Chem. 2015, 13, 1183-1195. [CrossRef]

22. Pérez, L.; Conde, E.; Domínguez, H. Microwave hydrodiffusion and gravity processing of Sargassum muticum. Process Biochem. 2014, 49, 981-988. [CrossRef]

23. Calcio Gaudino, E.; Tabasso, S.; Grillo, G.; Cravotto, G.; Dreyer, T.; Schories, G.; Altenberg, S.; Jashina, L.; Telysheva, G. Wheat straw lignin extraction with bio-based solvents using enabling technologies. Comptes Rendus Chim. 2018, 21, 563-571. [CrossRef]

24. Luque-García, J.; de Castro, M.L. Ultrasound: A powerful tool for leaching. TrAC Trends Anal. Chem. 2003, 22, 41-47. [CrossRef]

25. Lopes, G.; Barbosa, M.; Vallejo, F.; Gil-Izquierdo, Á.; Andrade, P.B.; Valentão, P.; Pereira, D.M.; Ferreres, F. Profiling phlorotannins from Fucus spp. of the Northern Portuguese coastline: Chemical approach by HPLC-DAD-ESI/MSn and UPLC-ESI-QTOF/MS. Algal Res. 2018, 29, 113-120. [CrossRef]

26. Cho, H.; Doan, T.; Ha, T.; Kim, H.; Lee, B.; Pham, H.; Cho, T.; Oh, W.; Cho, H.M.; Doan, T.P.; et al. Dereplication by HighPerformance Liquid Chromatography (HPLC) with Quadrupole-Time-of-Flight Mass Spectroscopy (qTOF-MS) and Antiviral Activities of Phlorotannins from Ecklonia cava. Mar. Drugs 2019, 17, 149. [CrossRef] [PubMed]

27. Cravotto, G.; Cintas, P. Forcing and Controlling Chemical Reactions with Ultrasound. Angew. Chem. Int. Ed. 2007, 46, 5476-5478. [CrossRef]

28. Grillo, G.; Boffa, L.; Talarico, S.; Solarino, R.; Binello, A.; Cavaglià, G.; Bensaid, S.; Telysheva, G.; Cravotto, G. Batch and Flow Ultrasound-Assisted Extraction of Grape Stalks: Process Intensification Design up to a Multi-Kilo Scale. Antioxidants 2020, 9, 730. [CrossRef]

29. Brand-Williams, W.; Cuvelier, M.E.; Berset, C. Use of a free radical method to evaluate antioxidant activity. Food Sci. Technol. 1995, 28, 25-30. [CrossRef]

30. Samorì, C.; Mazzei, L.; Ciurli, S.; Cravotto, G.; Grillo, G.; Guidi, E.; Pasteris, A.; Tabasso, S.; Galletti, P. Urease inhibitory potential and soil ecotoxicity of novel "polyphenols-deep eutectic solvents" formulations. ACS Sustain. Chem. Eng. 2019, 7, 15558-15567. [CrossRef]

31. Locatelli, M.; Gindro, R.; Travaglia, F.; Coïsson, J.D.; Rinaldi, M.; Arlorio, M. Study of the DPPH•-scavenging activity: Development of a free software for the correct interpretation of data. Food Chem. 2009, 114, 889-897. [CrossRef]

32. Lerche, D.; Sobisch, T. Direct and Accelerated Characterization of Formulation Stability. J. Dispers. Sci. Technol. 2011, 32, 1799-1811. [CrossRef]

33. EMA-European Medicines Agency. ICH Topic Q 1 A (R2) Stability Testing of new Drug Substances and Products Step. In Definitions 1-20. Available online: https:/ / www.ema.europa.eu/en/ich-q1a-r2-stability-testing-new-drug-substances-drugproducts (accessed on 20 October 2021).

34. Ansari, M.; Kazemipour, M.; Aklamli, M. The study of drug permeation through natural membranes. Int. J. Pharm. 2006, 327, 6-11. [CrossRef]

35. Campos, P.M.; Praça, F.S.G.; Bentley, M.V.L.B. Quantification of lipoic acid from skin samples by HPLC using ultraviolet, electrochemical and evaporative light scattering detectors. J. Chromatogr. B 2016, 1019, 66-71. [CrossRef]

36. Tommasi, E.; Cravotto, G.; Galletti, P.; Grillo, G.; Mazzotti, M.; Sacchetti, G.; Samorì, C.; Tabasso, S.; Tacchini, M.; Tagliavini, E. Enhanced and Selective Lipid Extraction from the Microalga P. tricornutum by Dimethyl Carbonate and Supercritical $\mathrm{CO}_{2}$ Using Deep Eutectic Solvents and Microwaves as Pretreatment. ACS Sustain. Chem. Eng. 2017, 5, 8316-8322. [CrossRef]

37. Calcio Gaudino, E.; Colletti, A.; Grillo, G.; Tabasso, S.; Cravotto, G. Emerging Processing Technologies for the Recovery of Valuable Bioactive Compounds from Potato Peels. Foods 2020, 9, 1598. [CrossRef]

38. Heffernan, N.; Brunton, N.P.; FitzGerald, R.J.; Smyth, T.J. Profiling of the molecular weight and structural isomer abundance of macroalgae-derived phlorotannins. Mar. Drugs 2015, 13, 509-528. [CrossRef] [PubMed]

39. Wijesinghe, W.A.J.P.; Jeon, Y.-J. Biological activities and potential cosmeceutical applications of bioactive components from brown seaweeds: A review. Phytochem. Rev. 2011, 10, 431-443. [CrossRef] 
40. Carreira-Casais, A.; Otero, P.; Garcia-Perez, P.; Garcia-Oliveira, P.; Pereira, A.G.; Carpena, M.; Soria-Lopez, A.; Simal-Gandara, J.; Prieto, M.A. Benefits and Drawbacks of Ultrasound-Assisted Extraction for the Recovery of Bioactive Compounds from Marine Algae. Int. J. Environ. Res. Public Health 2021, 18, 9153. [CrossRef]

41. Ummat, V.; Sivagnanam, S.P.; Rajauria, G.; O'Donnell, C.; Tiwari, B.K. Advances in pre-treatment techniques and green extraction technologies for bioactives from seaweeds. Trends Food Sci. Technol. 2021, 110, 90-106. [CrossRef]

42. Gouda, M.; Chen, K.; Li, X.; Liu, Y.; He, Y. Detection of microalgae single-cell antioxidant and electro-chemical potentials by gold microelectrode and Raman micro-spectroscopy combined with chemometrics. Sens. Actuators B Chem. 2021, 329, 129229-129239. [CrossRef]

43. Chen, Q.; Pan, X.-D.; Huang, B.-F.; Han, J.-L. Distribution of metals and metalloids in dried seaweeds and health risk to population in southeastern China. Sci. Rep. 2018, 8, 3578. [CrossRef]

44. Marzocchi, M.; Badocco, D.; Piovan, A.; Pastore, P.; Di Marco, V.; Filippini, R.; Caniato, R. Metals in Undaria pinnatifida (Harvey) Suringar and Sargassum muticum (Yendo) Fensholt edible seaweeds growing around Venice (Italy). J. Appl. Phycol. 2016, 28, 2605-2613. [CrossRef]

45. Davis, T.; Volesky, B.; Vieira, R.H.S. Sargassum seaweed as biosorbent for heavy metals. Water Res. 2000, 34, 4270-4278. [CrossRef]

46. Regolamento (CE) n. 1223/2009 del Parlamento Europeo e del Consiglio Europeo sui prodotti cosmetici. Gazz. Uff. Dell'Unione Eur. (L342/59). 2009; pp. 52-59. Available online: https://www.salute.gov.it/imgs/C_17_pagineAree_145_listaFile_itemName_ $0 \_$file.pdf (accessed on 20 October 2021).

47. Signoretto, M.; Ghedini, E.; Menegazzo, F. Formulato Cosmetico a Rilascio Controllato di Principi Attivi. International Patent No. PCT/IB2019/053710, 7 May 2019.

48. Lee, K.Y.; Mooney, D.J. Alginate: Properties and biomedical applications. Prog. Polym. Sci. 2012, 37, 106-126. [CrossRef]

49. Sachan, N.; Pushkar, S.; Jha, A.; Bhattcharya, A. Sodium alginate: The wonder polymer for controlled drug delivery. J. Pharm. Res. 2009, 2, 1191-1199.

50. Lupi, F.R.; Gabriele, D.; Seta, L.; Baldino, L.; De Cindio, B. Rheological investigation of pectin-based emulsion gels for pharmaceutical and cosmetic uses. Rheol. Acta 2015, 54, 41-52. [CrossRef]

51. Lademann, J.; Jacobi, U.; Surber, C.; Weigmann, H.-J.; Fluhr, J.W. The tape stripping procedure-evaluation of some critical parameters. Eur. J. Pharm. Biopharm. 2009, 72, 317-323. [CrossRef] [PubMed] 